\title{
Oxoperoxo Vanadium(V) Complexes of L-Lactic Acid: Density Functional Theory Study of Structure and NMR Chemical Shifts
}

\author{
Licínia L. G. Justino,, ${ }^{, t, \neq}$ M. Luísa Ramos, ${ }^{\dagger, \ddagger}$ Fernando Nogueira, ${ }^{\S}$ Abilio J. F. N. Sobral, ${ }^{\dagger}$ \\ Carlos F. G. C. Geraldes, ${ }^{\ddagger, l}$ Martin Kaupp,${ }^{\perp}$ Hugh D. Burrows, ${ }^{\dagger}$ Carlos Fiolhais,,${ }^{\S}$ and Victor M. S. Gil ${ }^{\dagger}$ \\ Departamento de Química, Faculdade de Ciências e Tecnologia, Universidade de Coimbra, \\ 3004-535 Coimbra, Portugal, Departamento de Física e Centro de Física Computacional, \\ Faculdade de Ciências e Tecnologia, Universidade de Coimbra, 3004-516 Coimbra, Portugal, \\ Departamento de Bioquímica, Faculdade de Ciências e Tecnologia, Universidade de Coimbra, \\ 3001-401 Coimbra, Portugal, Centro de Neurociências e Biologia Celular, Universidade de \\ Coimbra, Portugal, and Institut für Anorganische Chemie, Universität Würzburg, Am Hubland, \\ D-97074 Würzburg, Germany
}

Received March 5, 2008

\begin{abstract}
Various combinations of density functionals and pseudopotentials with associated valence basis-sets are compared for reproducing the known solid-state structure of $\left[\mathrm{V}_{2} \mathrm{O}_{2}(\mathrm{OO})_{2} \mathrm{~L}-\mathrm{lact}_{2}\right]^{2-}$ cis. Gas-phase optimizations at the B3LYP/ SBKJC level have been found to provide a structure that is close to that seen in the solid state by X-ray diffraction. Although this may result in part from error compensation, this optimized structure allowed satisfactory reproduction of solution multinuclear NMR chemical shifts of the complex in all-electron DFT-IGLO calculations (UDFT-IGLOPW91 level), suggesting that it is probably close to that found in solution. This combination of approaches has subsequently been used to optimize the structures of the vanadium oxoperoxo complexes $\left[\mathrm{V}_{2} \mathrm{O}_{3}(\mathrm{OO})\left\llcorner-\mathrm{lact}_{2}\right]^{2-}\right.$ cis, $\left[\mathrm{V}_{2} \mathrm{O}_{3}(\mathrm{OO}) \mathrm{L}-\mathrm{lact} 2\right]^{2-}$ trans, and $\left[\mathrm{VO}(\mathrm{OO})(\mathrm{L}-\mathrm{lact})\left(\mathrm{H}_{2} \mathrm{O}\right)\right]^{-}$cis. The ${ }^{1} \mathrm{H},{ }^{13} \mathrm{C},{ }^{51} \mathrm{~V}$, and ${ }^{17} \mathrm{O}$ NMR chemical shifts for these complexes have been calculated and compared with the experimental solution chemical shifts. Excellent agreement is seen with the ${ }^{13} \mathrm{C}$ chemical shifts, while somewhat inferior agreement is found for ${ }^{1} \mathrm{H}$ shifts. The ${ }^{51} \mathrm{~V}$ and ${ }^{17} \mathrm{O}$ chemical shifts of the dioxo vanadium centers are well reproduced, with differences between theoretical and experimental shifts ranging from 22.9 to $35.6 \mathrm{ppm}$ and from 25.1 to $43.7 \mathrm{ppm}$, respectively. Inferior agreement is found for oxoperoxo vanadium centers, with differences varying from 137.3 to $175.0 \mathrm{ppm}$ for ${ }^{51} \mathrm{~V}$ shifts and from 148.7 to $167.0 \mathrm{ppm}$ for ${ }^{17} \mathrm{O}$ (oxo) shifts. The larger errors are likely to be due to overestimated peroxo $\mathrm{O}-\mathrm{O}$ distances. The chosen methodology is able to predict and analyze a number of interesting structural features for vanadium(V) oxoperoxocomplexes of $\alpha$-hydroxycarboxylic acids.
\end{abstract}

\section{Introduction}

Vanadium occurs in nature as a trace element. It is essential for several organisms. In particular, it is implicated in the synthesis of chlorophyll in green plants and in the

* To whom correspondence should be addressed. E-mail: liciniaj@ qui.uc.pt. Tel: +351-239-854453. Fax: +351-239-827703.

† Departamento de Química, Faculdade de Ciências e Tecnologia, Universidade de Coimbra.

Centro de Neurociências e Biologia Celular, Universidade de Coimbra

$\S$ Departamento de Física e Centro de Física Computacional, Faculdade de Ciências e Tecnologia, Universidade de Coimbra.

"Departamento de Bioquímica, Faculdade de Ciências e Tecnologia, Universidade de Coimbra.

${ }^{\perp}$ Universität Würzburg. normal growth of some animals ${ }^{1}$ and may also be essential for humans. ${ }^{2}$ In recent decades, in vivo and in vitro studies of the biological effects of this metal have revealed other important effects, both at the whole organ and cellular levels. These include the ability to inhibit certain enzymes, such as phosphatases, ATPases, phosphotransferases, nucleases, and kinases, the possibility of mimicking the effects of insulin, in addition to their capacity to reduce cholesterol biosynthesis and triglyceride levels in blood plasma and, consequently, to reduce the incidence of cardiovascular diseases. Further,

(1) Rehder, D. Angew. Chem., Int. Ed. Engl. 1991, 30, 148-167; and references therein.

(2) Crans, D. C.; Smee, J. J.; Gaidamauskas, E.; Yang, L. Chem. Rev. 2004, 104, 849-902; and references therein.

Inorganic Chemistry, Vol. 47, No. 16, 2008 
they show the ability to enhance mineralization in teeth and bones, ${ }^{3}$ and may have antitumorigenic properties. ${ }^{4,5}$ Vanadium is present at the active site of certain enzymes, including a vanadium nitrogenase in the nitrogen-fixing bacterium Azotobacter, and haloperoxidases present in lichens and marine algae. ${ }^{1,2}$ Haloperoxidases catalyze the oxidation of halides by hydrogen peroxide and are thought to be involved in the biosynthesis of a large number of marine natural products, many of which have potent antifungal, antibacterial, antineoplastic, antiviral (e.g., anti-HIV) and anti-inflammatory properties. ${ }^{6}$

Vanadium chemistry is characterized by the presence of a multiplicity of oxidation states. Of the six known oxidation states for this metal, only the $+3,+4$, and +5 ones are important at the biological level, with the tetra and pentavalent ones being the most common. The oxidation states below +3 are generally too reducing to exist in aqueous medium at neutral $\mathrm{pH}^{7}$ Peroxo vanadium(V) complexes have, for several years, been the object of particularly intense investigation. These complexes show antitumorigenic ${ }^{5}$ activity and also enhanced insulinomimetic ${ }^{2,8}$ activity compared with the anionic salts of the higher oxidation states of vanadium. Additionally, these complexes have been studied as functional models ${ }^{9-11}$ for the haloperoxidase enzymes and are efficient oxidants for a variety of substrates, including benzene and other aromatics, alkenes, allylic alcohols, sulfides, halides, primary and secondary alcohols. ${ }^{12-14}$

Peroxovanadium complexes with $\alpha$-hydroxycarboxylic acids are of particular biochemical relevance, since many of these exist in biological media and are involved in several basic physiological processes.

In the past, we reported a study ${ }^{15}$ of the system $\mathrm{V}(\mathrm{V})-\mathrm{L}-$ lactic acid $-\mathrm{H}_{2} \mathrm{O}_{2}$ in aqueous solution using multinuclear NMR spectroscopy and proposed structures for the corresponding peroxovanadium $(\mathrm{V})$ complexes. The solid-state structure of one of these complexes has been presented, ${ }^{16}$ but detailed information is lacking on the structures of the other complexes found in aqueous solution. In this study, we have applied density functional theory (DFT) to study the structures and to simulate the solution NMR chemical shifts of the complexes. The comparison between the theoretical NMR chemical shifts and the experimental values affords, in principle, an excellent means of structural

(3) Chasteen, N. D. Struct. Bonding (Berlin) 1983, 53, 105-138.

(4) Djordjevic, C. Met. Ions Biol. Syst. 1995, 31, 595-616.

(5) Evangelou, A. M. Crit. Rev. Oncol. Hemat. 2002, 42, 249-265.

(6) Butler, A.; Walker, J. V. Chem. Rev. 1993, 93, 1937-1944.

(7) Butler, A.; Carrano, C. J. Coord. Chem. Rev. 1991, 109, 61-105.

(8) Thompson, K. H.; McNeill, J. H.; Orvig, C. Chem. Rev. 1999, 99, $2561-2572$.

(9) Colpas, G. J.; Hamstra, B. J.; Kampf, J. W.; Pecoraro, V. L. J. Am. Chem. Soc. 1994, 116, 3627-3628.

(10) Colpas, G. J.; Hamstra, B. J.; Kampf, J. W.; Pecoraro, V. L. J. Am. Chem. Soc. 1996, 118, 3469-3478.

(11) Kanamori, K.; Nishida, K.; Miyata, N.; Okamoto, K. Chem. Lett. 1998 $1267-1268$.

(12) Hirao, T. Chem. Rev. 1997, 97, 2707-2724.

(13) Bolm, C. Coord. Chem. Rev. 2003, 237, 245-256.

(14) Tsuchida, E.; Oyaizu, K. Coord. Chem. Rev. 2003, 237, 213-228.

(15) Justino, L. L. G.; Ramos, M. L.; Caldeira, M. M.; Gil, V. M. S. Eur. J. Inorg. Chem. 2000, 1617-1621.

(16) Schwendt, P.; Švančárek, P.; Smatanová, I.; Marek, J. J. Inorg. Biochem. 2000, 80, 59-64.

\section{Scheme 1}

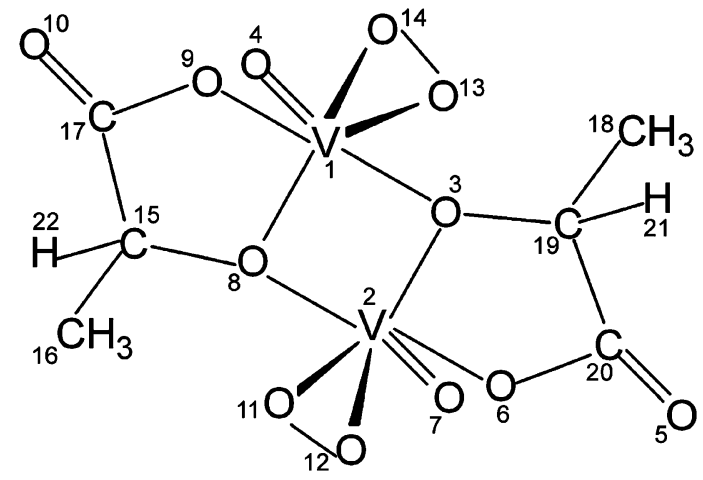

evaluation, in addition to validation of the computational methods used for determining the geometries and for calculating the NMR parameters. We have also analyzed the ability of DFT methods to predict some structural aspects of these and other complexes of $\alpha$-hydroxycarboxylic acids.

\section{Computational Details}

The molecular structures were optimized at the DFT level without symmetry constraints using the GAMESS code. ${ }^{17} \mathrm{We}$ have chosen the known X-ray structure and solution NMR parameters of the complex $\left[\mathrm{V}_{2} \mathrm{O}_{2}(\mathrm{OO})_{2} \mathrm{~L}_{-} \mathrm{lact}_{2}\right]^{2-}{ }_{\text {cis }}(\mathbf{L}-\mathbf{2}$ cis; cf. Scheme 1$)$ to evaluate the performance of different density functionals and pseudopotential/ basis-set combinations for reproducing the solid-state structures and solution NMR shifts of $\mathrm{V}(\mathrm{V})$ oxo and oxoperoxo complexes. The exchange-correlation functionals compared were the B3LYP (Becke three-parameter Lee-Yang-Parr) ${ }^{18,19}$ and the BHHLYP (mixing $50 \%$ Hartree-Fock $+50 \%$ B 88 exchange, ${ }^{20}$ augmented by LYP ${ }^{19}$ correlation) hybrid functionals, together with the BLYP ${ }^{19,20}$ GGA functional. We have also evaluated the PBELYP ${ }^{19,21-23}$ GGA functional and BVWN (B88 ${ }^{20}$ GGA exchange with VWN ${ }^{24}$ LDA correlation).

Different pseudopotentials with associated valence basis-sets for the metal and ligand basis sets were studied: (a) the relativistic SBKJC $^{25,26}$ effective core potentials (ECPs) and basis sets for V, $\mathrm{C}$, and $\mathrm{O}$ (and Mo in one case), with the $31 \mathrm{G}$ basis for $\mathrm{H}$; (b) the relativistic small-core (RSC 1997) ECPs from the Stuttgart group ("SDD") $)^{27}$ and $(8 \mathrm{~s} 7 \mathrm{p} 6 \mathrm{~d}) /[6 \mathrm{~s} 5 \mathrm{p} 3 \mathrm{~d}]$ valence basis for $\mathrm{V}$, with $6-311 \mathrm{G}^{*}$ basis sets for $\mathrm{O}, \mathrm{C}$, and $\mathrm{H}^{28}$ (c) the all-electron Wachters $+\mathrm{f}(14 \mathrm{~s} 11 \mathrm{p} 6 \mathrm{~d} 3 \mathrm{f}) /[8 \mathrm{~s} 6 \mathrm{p} 4 \mathrm{~d} 1 \mathrm{f}]$ basis set for $\mathrm{V},{ }^{29-31}$ again with the $6-311 \mathrm{G}^{*}$ basis for $\mathrm{O}, \mathrm{C}$, and $\mathrm{H}$.

(17) Schmidt, M. W.; Baldridge, K. K.; Boatz, J. A.; Elbert, S. T.; Gordon, M. S.; Jensen, J. H.; Koseki, S.; Matsunaga, N.; Nguyen, K. A.; Su, S. J.; Windus, T. L.; Dupuis, M.; Montgomery, J. A. J. Comput. Chem. 1993, 14, 1347-1363.

(18) Becke, A. D. J. Chem. Phys. 1993, 98, 5648-5652.

(19) Lee, C.; Yang, W.; Parr, R. G. Phys. Rev. B 1988, 37, 785-789.

(20) Becke, A. D. Phys. Rev. 1988, A38, 3098-3100.

(21) In GAMESS only the exchange PBE functional is implemented, which is why this was used in combination with the correlation functional LYP.

(22) Perdew, J. P.; Burke, K.; Ernzerhof, M. Phys. Rev. Lett. 1996, 77, 3865-3868; Erratum: 1997, 78, 1396-1396.

(23) Ernzerhof, M.; Scuseria, G. E. J. Chem. Phys. 1999, 110, 5029-5036.

(24) Vosko, S. H.; Wilk, L.; Nusair, M. Can. J. Phys. 1980, 58, 12001211.

(25) Stevens, W. J.; Krauss, M.; Basch, H.; Jasien, P. G. Can. J. Chem. 1992, 70, 612-630.

(26) Cundari, T. R.; Stevens, W. J. J. Chem. Phys. 1993, 98, 5555-5565.

(27) Dolg, M.; Wedig, U.; Stoll, H.; Preuss, H. J. Chem. Phys. 1987, 86, 866-872.

(28) Krishnan, R.; Binkley, J. S.; Seeger, R.; Pople, J. A. J. Chem. Phys. 1980, 72, 650-654.

(29) Wachters, A. J. H. J. Chem. Phys. 1970, 52, 1033-1036. 
The gradient threshold for optimizations was taken as $10^{-5}$ hartree $b \mathrm{hoh}^{-1}$. In the optimization, we started using data from the $\mathrm{X}$-ray crystallographic structure. The structure was also optimized by molecular mechanics calculations, using the $\mathrm{MM}+$ force field, with HyperChem v6.03 software from Hypercube Inc., U.S.A., and a Polak-Ribiere conjugated gradient algorithm for energy minimization with a final gradient of $0.05 \mathrm{kcal} / \mathrm{A}$ mol. Optimization was made in a box of 256 water molecules. The relative energies of isomers presented in the discussion include zero-point vibrational energy corrections.

On the basis of the optimized structures, nuclear shieldings have been computed at the DFT level ${ }^{32-36}$ with individual gauges for localized orbitals (IGLO). ${ }^{37}$ These calculations used the deMon $\operatorname{program}^{38,39}$ (including the deMon-NMR modules ${ }^{40,41}$ ), and the PW91 ${ }^{42-44}$ gradient-corrected functional. The calculations employed a 9s7p4d all-electron basis for $\mathrm{V},{ }^{27,45,46}$ the IGLO-II ${ }^{37}$ all electron basis sets for $\mathrm{O}, \mathrm{C}$, and $\mathrm{H}$, and a fine integration grid (FINE option). In addition to the standard uncoupled DFT (UDFT) equations arising from the use of a GGA functional, ${ }^{32-36}$ we have also evaluated the "Malkin correction" in its LOC1 approximation within the sum-over-states density-functional perturbation theory (SOSDFPT) approach. ${ }^{40,41}$ However, the effect on the most relevant ${ }^{51} \mathrm{~V}$ and ${ }^{17} \mathrm{O}$ shifts was minimal, and we only present the UDFT results. ${ }^{13} \mathrm{C}$ and ${ }^{1} \mathrm{H}$ relative chemical shifts $(\delta)$ are given with respect to the absolute shielding values $(\sigma)$ of tetramethylsilane (TMS) obtained at the same computational level, while ${ }^{51} \mathrm{~V}$ shifts are given with respect to the shielding value of $\mathrm{VOCl}_{3}$. Calculated ${ }^{17} \mathrm{O}$ nuclear shieldings have been converted to chemical shifts using a shielding value of $+290.9 \mathrm{ppm}$ for liquid water at room temperature, derived from the absolute shielding scale of ref 47 .

\section{Results and Discussion}

I. Validation for L-2cis. To decide which method is best to clarify details of our previously proposed structures of the $\mathrm{V}(\mathrm{V})-\mathrm{L}$-lactic acid- $\mathrm{H}_{2} \mathrm{O}_{2}$ complexes, ${ }^{15}$ we have used DFT and MM at different theoretical levels to optimize the

(30) Wachters, A. J. H. IBM Tech. Rept. 1969, RJ584.

(31) Bauschlicher, C. W.; Langhoff, S. R.; Barnes, L. A. J. Chem. Phys. 1989, 91, 2399-2411.

(32) Malkin, V. G.; Malkina, O. L.; Salahub, D. R. Chem. Phys. Lett. 1993, $204,80-86$.

(33) Malkin, V. G.; Malkina, O. L.; Salahub, D. R. Chem. Phys. Lett. 1993, 204, 87-95.

(34) Schreckenbach, G.; Ziegler, T. J. Phys. Chem. 1995, 99, 606-611.

(35) Rauhut, G.; Puyear, S.; Wolinski, K.; Pulay, P. J. Phys. Chem. 1996, $100,6310-6316$.

(36) Cheeseman, J. R.; Trucks, G. W.; Keith, T. A.; Frisch, M. J. Chem. Phys. 1996, 104, 5497-5509.

(37) Kutzelnigg, W.; Fleischer, U.; Schindler, M. NMR-Basic Principles and Progress; Springer: Heidelberg, 1990; Vol. 23, p 167.

(38) Salahub, D. R.; Fournier, R.; Mlynarski, P.; Papai, I.; St-Amant A.; Ushio, J. Density Functional Methods in Chemistry. Labanowski, J., Andzelman, J., Eds.; Springer: New York, 1991.

(39) St-Amant, A.; Salahub, D. R. Chem. Phys. Lett. 1990, 169, 387-392.

(40) Malkin, V. G.; Malkina, O. L.; Casida, M. E.; Salahub, D. R. J. Am. Chem. Soc. 1994, 116, 5898-5908.

(41) Malkin, V. G.; Malkina, O. L.; Eriksson, L. A.; Salahub, D. R. Modern Density Functional Theory: A Tool for Chemistry. In Theoretical and Computational Chemistry; Seminario, J. M., Politzer P., Eds.; Elsevier: Amsterdam, 1995; Vol. 2.

(42) Perdew, J. P.; Wang, Y. Phys. Rev. B. 1992, 45, 13244-13249.

(43) Perdew, J. P. In Electronic Structure of Solids; Ziesche, P., Eischrig, H., Eds.; Akademie Verlag: Berlin, 1991.

(44) Perdew, J. P.; Chevary, J. A.; Vosko, S. H.; Jackson, K. A.; Pederson, M. R.; Singh, D. J.; Fiolhais, C. Phys. Rev. B. 1992, 46, 6671-6687.

(45) Schäfer, A.; Horn, H.; Ahlrichs, R. J. Chem. Phys. 1992, 97, 25712577.

(46) Munzarová, M.; Kaupp, M. J. Phys. Chem. A 1999, 103, 9966-9983. structure of $\left[\mathrm{V}_{2} \mathrm{O}_{2}(\mathrm{OO})_{2} \mathrm{~L}-\mathrm{lact}_{2}\right]^{2-}{ }_{\text {cis }}(\mathbf{L}-\mathbf{2 c i s})$ (Scheme 1). This is the only peroxocomplex found in the solid state for this system ${ }^{16}$ and is also one of the complexes formed with this system in aqueous solution. The results obtained in the gas phase at the different theoretical levels are compared with the experimental data for the solid-state structure in Table 1.

In general, reasonable agreement is seen between the results obtained at various DFT calculation levels and the $\mathrm{X}$-ray diffraction data. The only major divergence comes with the $\mathrm{O}(11)-\mathrm{O}(12)$ distance, where we feel that the experimental value is anomalously short. This is probably an artifact due to disorder in the crystal, as observed for other oxomonoperoxo complexes of $\mathrm{V}(\mathrm{V}) .{ }^{48}$ In all other cases, the differences between the theoretical and experimental bond lengths are within the order of a few hundredths of an angstrom, and the bond angles agree within a few degrees. It can also be noted that the computations predict an almost symmetrical structure (with effective $C_{2}$ symmetry) for the complex, whereas the $\mathrm{X}$-ray structure is asymmetrical. This is not unexpected because the solid-state asymmetry is probably caused by crystal packing induced intermolecular interactions, which are absent in the gas phase (isolated molecule) conditions used in these calculations. Results obtained with PBELYP and BVWN functionals are close to the BLYP data and are omitted here.

The overall differences among the parameters obtained by the various methods are relatively minor and depend somewhat on the structural parameters considered. If we start with the $\mathrm{V}-\mathrm{O}$ distances, we note that the DFT calculations tend to overestimate the distances to the carboxylato and hydroxo oxygen atoms of the ligands. This is not unexpected and is partly due to the neglect of the electrostatic influence of the crystal environment. The overestimation is most pronounced at the GGA level and improved by increasing exact-exchange admixture such that BHHLYP provides the closest agreement with experiment. The influence of the pseudopotential and the basis set is moderate: The SDD pseudopotential results are in excellent agreement with the all-electron ("WACHTERS") results, confirming the good performance of these ECPs, and, probably, the relatively low importance of scalar relativistic effects for the early $3 \mathrm{~d}$ element vanadium. The SBKJC bond lengths are slightly shorter here and thus move the distances fortuitously somewhat closer to the experimental values. This will be important for the subsequent discussion.

The short $\mathrm{V}=\mathrm{O}$ distances to the oxo ligands exhibit a smaller variation between experiment and the different computational results. However, as we expect them to be particularly important for the $\left({ }^{51} \mathrm{~V}\right.$ and $\left.{ }^{17} \mathrm{O}(\mathrm{V}=\mathrm{O})\right)$ NMR shifts, they have a considerable weight in our considerations: We can consider that the (presumably) most accurate SDDECP and all-electron calculations give too short distances

(47) Sundholm, D.; Gauss, J.; Schäfer, A. J. Chem. Phys. 1996, 105, 1105111059.

(48) Butler, A.; Clague, M. J.; Meister, G. E. Chem. Rev. 1994, 94, 625638. 
Justino et al.

Table 1. Selected Geometrical Parameters (Bond Lengths in $\AA$, Bond Angles in deg) of $\left[\mathrm{V}_{2} \mathrm{O}_{2}(\mathrm{OO})_{2}(\mathrm{~L}-\mathrm{lact})_{2}\right]^{2-}(\mathbf{L}-2$ cis $)$

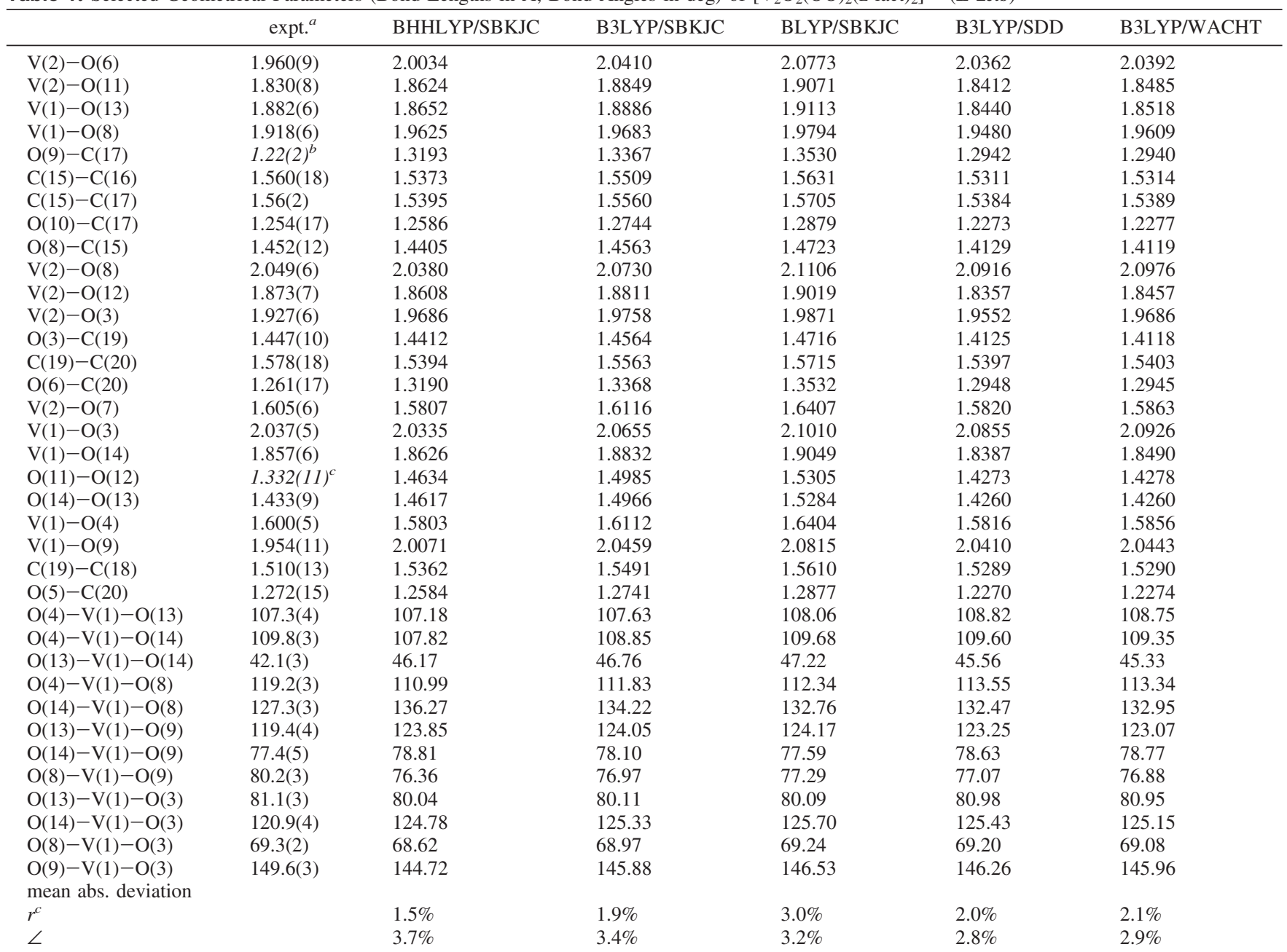

${ }^{a}$ From ref $16 .{ }^{b}$ Anomalously short bond (cf. text). ${ }^{c}$ The $\mathrm{O}(9)-\mathrm{C}(17)$ and $\mathrm{O}(11)-\mathrm{O}(12)$ distances have been excluded here, as the experimental values are too short which probably arises from disorder in the crystal. ${ }^{48}$

when employed with B3LYP. The fact that the SBKJC distances are slightly longer and closer to the experimental data is probably fortuitous.

The distances between peroxo oxygen atoms and vanadium exhibit a dependence on the functional closer to the $\mathrm{V}-\mathrm{O}$ (hydroxo) and $\mathrm{V}-\mathrm{O}$ (carboxylato) distances yet with slightly too short distances at B3LYP/WACHTERS and B3LYP/SDD levels. The B3LYP/SBKJC value is slightly too long, and we expect that BHHLYP/SBKJC would provide the best overall agreement. Finally, the peroxo $\mathrm{O}-\mathrm{O}$ distances tend to be overestimated, except for the B3LYP/ SDD and B3LYP/WACHTERS levels. Only the $\mathrm{O}(13)-\mathrm{O}(14)$ distance can be compared, but we expect identical behavior for $\mathrm{O}(11)-\mathrm{O}(12)$. We note that there is only a relatively small variation for the other intra-ligand distances and the angles.

Because we wish to reproduce condensed-phase NMR data, our selection of a suitable computational protocol to be applied to the other complexes studied (see below) has to consider, in particular, those structural parameters that are expected to influence the shifts most markedly. This premise holds true both for $\mathrm{V}-\mathrm{O}$ distances, in particular the $\mathrm{V}=\mathrm{O}$ (oxo) bond lengths, and also the peroxo $\mathrm{O}-\mathrm{O}$ distance. In general, the B3LYP/SBKJC level appears to provide a reasonable compromise and seems to be a good choice. The exception involves the peroxo group, where too long peroxo $\mathrm{O}-\mathrm{O}$ bond lengths are predicted at this level. This will affect the ${ }^{17} \mathrm{O}$ shifts of the peroxo ligands (see below). We note in passing that differences between the MM and the X-ray structural parameters are slightly larger. We have also tested the effect of the solvent by optimizing the structure of the complex in a box of 256 water molecules at the MM level. However, the equilibrium geometry does not appear to be affected by the presence of the solvent (the results are not shown for simplicity).

These considerations will now be developed further through computing NMR shifts for $\mathbf{L - 2}$ cis. Table 2 reports computed chemical shifts for various nuclei of $\mathbf{L}-\mathbf{2 c i s}$ in comparison with experimental solution NMR data. In addition to excluding rovibrational and environmental effects on the structures, these calculations also neglect environmental effects on the shifts at a given structure and assume that the chosen UDFT-IGLO-PW91 level with associated basis sets (see Computational Details) is adequate. ${ }^{49}$ On the basis of previous MD-simulations, for the ${ }^{51} \mathrm{~V}$ shifts, neglect of

(49) Bühl, M.; Kaupp, M.; Malkina, O. L.; Malkin, V. G. J. Comput. Chem. 1999, 20, 91-105; and references therein. 
Table 2. Comparison of Experimental and Computed Isotropic Chemical Shifts ${ }^{a}$ for the Different DFT Optimized Structures of L-2cis

\begin{tabular}{|c|c|c|c|c|c|c|}
\hline site $^{b}$ & expt./ $/ \mathrm{H}_{2} \mathrm{O}^{c}$ & $\mathrm{BH} / \mathrm{SBKJC}^{d}$ & $\mathrm{~B} 3 / \mathrm{SBKJC}^{d}$ & ${\mathrm{BL} / \mathrm{SBKJC}^{d}}^{d}$ & B3/SDD & B3/WACHT \\
\hline $\mathrm{V}(1) / \mathrm{V}(2)$ & -595.9 & -425.1 & -420.9 & -404.2 & -369.1 & -373.2 \\
\hline $\mathrm{O}(4) / \mathrm{O}(7)$ & 1179.0 & 966.5 & 1030.3 & 1093.6 & 969.5 & 980.1 \\
\hline $\mathrm{O}(11) / \mathrm{O}(13)$ & & 649.6 & 711.2 & 773.1 & 627.0 & 637.7 \\
\hline $\mathrm{C}(15) / \mathrm{C}(19)$ & 80.39 & 85.34 & 88.62 & 91.81 & 86.73 & 86.54 \\
\hline $\mathrm{C}(16) / \mathrm{C}(18)$ & 19.88 & 20.31 & 21.15 & 21.11 & 21.24 & 21.40 \\
\hline $\mathrm{C}(17) / \mathrm{C}(20)$ & 188.44 & 182.40 & 184.58 & 187.03 & 176.81 & 177.00 \\
\hline
\end{tabular}

${ }^{a}$ Chemical shifts computed at the UDFT-IGLO-PW91 level with a 9s7p4d basis set for vanadium and IGLO-II basis sets for $\mathrm{C}, \mathrm{O}$, and $\mathrm{H} .{ }^{51} \mathrm{~V},{ }^{13} \mathrm{C}$, and ${ }^{1} \mathrm{H}$ isotropic chemical shifts are given with respect to the calculated shielding values of $\mathrm{VOCl}_{3}$ and TMS $(\mathrm{BH} / \mathrm{SBKJC}: \sigma(\mathrm{V})=-1806.4 \mathrm{ppm}, \sigma(\mathrm{C})=185.37$ ppm, $\sigma(\mathrm{H})=30.85 \mathrm{ppm}$; B3/SBKJC: $\sigma(\mathrm{V})=-1945.7 \mathrm{ppm}, \sigma(\mathrm{C})=182.96 \mathrm{ppm}, \sigma(\mathrm{H})=30.54 \mathrm{ppm}$; BL/SBKJC: $\sigma(\mathrm{V})=-2076.29 \mathrm{ppm}, \sigma(\mathrm{C})=$ $181.07 \mathrm{ppm}, \sigma(\mathrm{H})=30.30 \mathrm{ppm}$; B3/SDD: $\sigma(\mathrm{V})=-1756.3 \mathrm{ppm}, \sigma(\mathrm{C})=188.16 \mathrm{ppm}, \sigma(\mathrm{H})=31.28 \mathrm{ppm} ; \mathrm{B} 3 / \mathrm{WACHT}: \sigma(\mathrm{V})=-1797.7 \mathrm{ppm}, \sigma(\mathrm{C})=$ $188.16 \mathrm{ppm}, \sigma(\mathrm{H})=31.28 \mathrm{ppm}){ }^{b}$ Very minor differences were found for formally symmetry-equivalent sites due to imperfections of the optimized geometries (respectively, at the different calculation levels, $\pm 1.2,1.0,0.4,1.7$ and $2.0 \mathrm{ppm}$ for $\mathrm{V}(1) / \mathrm{V}(2) ; \pm 1.0,0.7,0.7,0.4 \mathrm{and} 0.4 \mathrm{ppm}$ for $\mathrm{O}(4) / \mathrm{O}(7) ; \pm 3.3,5.5$, 7.4, 4.6 and $4.3 \mathrm{ppm}$ for $\mathrm{O}(11) / \mathrm{O}(13) ; \pm 2.0,2.0,1.6,2.5$ and $2.9 \mathrm{ppm}$ for $\mathrm{O}(12) / \mathrm{O}(14) ; \pm 0.34,0.47,0.57,0.84$ and $0.86 \mathrm{ppm}$ for $\mathrm{C}(15) / \mathrm{C}(19) ; \pm 0.40$, $0.85,0.44,0.39,0.42 \mathrm{ppm}$ for $\mathrm{C}(16) / \mathrm{C}(18) ; \pm 0.32,0.30,0.27,0.35$ and $0.43 \mathrm{ppm}$ for $\mathrm{C}(17) / \mathrm{C}(20) ; \pm 0.02,0.04,0.05,0.05$ and $0.04 \mathrm{ppm}$ for $\mathrm{H}(21) / \mathrm{H}(22)$; $\pm 0.01,0.02,0.03,0.05$ and $0.04 \mathrm{ppm}$ for $\underline{\mathrm{H}}_{3}-\mathrm{C}(16) / \underline{\mathrm{H}}_{3}-\mathrm{C}(18) .{ }^{c}$ From ref $15 .{ }^{d} \mathrm{BH}, \mathrm{B} 3$, and BL stand for BHHLYP, B3LYP and BLYP functionals, respectively.

vibrational effects is expected to give rise to errors on the order of tens of ppm. ${ }^{50}$

Overall, we note that the computed ${ }^{51} \mathrm{~V}$ shifts are clearly too shielded (typically by about $170-200 \mathrm{ppm}$ ), and the ${ }^{17} \mathrm{O}(\mathrm{V}=\mathrm{O})$ shifts also appear to be partly shielded. These shifts depend appreciably on the $\mathrm{V}-\mathrm{O}$ bond lengths. As B3LYP/SBKJC provides a good compromise for metal-ligand distances, these structures perform somewhat better than most of the others for the metal shieldings (BHHLYP/SBKJC structures are slightly better for ${ }^{51} \mathrm{~V}$ but slightly worse for ${ }^{17} \mathrm{O}$ shifts, and BLYP/SBJKC structures are somewhat better for the ${ }^{17} \mathrm{O}$ shifts but overall inferior for the carbon and vanadium shifts; cf. Table 2).

II. Tests for Further Complexes. The B3LYP/SBKJC level provides a reasonable overall compromise and will be used to study the structures of the complexes of ref 15 , followed by UDFT-IGLO-PW91 calculations of the NMR chemical shifts. No ${ }^{17} \mathrm{O}$ data for coordinated peroxo ligands were available for $\mathbf{L - 2 c i s ; ~ w e ~ e x p e c t ~ s o m e w h a t ~ l a r g e r ~ e r r o r s ~}$ here because of the somewhat too long $\mathrm{O}-\mathrm{O}$ distance at the given level. Figure 1 shows the structures of the four complexes optimized at the B3LYP/SBKJC level, while Table 3 presents some geometrical parameters for the complexes L-1cis, L-1trans, and L-3cis. The structure of L-2cis has already been given in Table 1 .

In the past, ${ }^{15}$ we have proposed structures for the L-lactic acid oxoperoxo vanadium(V) complexes which have sevencoordinated oxoperoxo metal centers. During the present optimization of these structures we have found that in every case a water molecule has been expelled from the coordination sphere of the seven-coordinated centers, leading to sixcoordinated centers together with externally hydrogenbonded water molecules. A similar result has been obtained by Bühl and co-workers ${ }^{50}$ in the DFT optimization of $\left[\mathrm{VO}\left(\mathrm{O}_{2}\right)_{2}\left(\mathrm{H}_{2} \mathrm{O}\right)_{2}\right]^{-}$, which converged to produce $\left[\mathrm{VO}\left(\mathrm{O}_{2}\right)_{2}{ }^{-}\right.$ $\left.\left(\mathrm{H}_{2} \mathrm{O}\right)\right]^{-}$. Bagno and co-workers ${ }^{51}$ had previously concluded, using DFT and Hartree-Fock calculations, that the maxi-

(50) Bühl, M.; Parrinello, M. Chem--Eur. J. 2001, 7, 4487-4494; and references therein.

(51) Bagno, A.; Conte, V.; Di Furia, F.; Moro, S. J. Phys. Chem. A 1997, 101, 4637-4640. mum stabilization of the oxoperoxo complex [VO$\left.\left(\mathrm{O}_{2}\right)\left(\mathrm{H}_{2} \mathrm{O}\right)_{n}\right]^{+}$in the gas phase occurs for $n=3$, that is, at a coordination number of six. In the solid state with $\alpha$-hydroxycarboxylic acids, $\mathrm{V}(\mathrm{V})$ forms pentagonal pyramidal oxoperoxo complexes (six-coordinated) in some cases and, in other cases, pentagonal bipyramidal oxoperoxo complexes (seven-coordinated) (e.g., refs 52 and 53). The geometries shown in Figure 1 are the result of reoptimization after the hydrogen bonded water molecules have been removed. The isomerism between $\mathbf{L}-\mathbf{1}$ cis and $\mathbf{L}-\mathbf{1}$ trans results from the fact that the $\mathrm{CHOH}$ carbon of lactic acid is asymmetric, thus allowing two different orientations of the acid relative to the $\mathrm{V}=\mathrm{O}$ bond of the oxoperoxo center. In our previous paper, ${ }^{15}$ based on incomplete information on the system, a different nature of the isomerism was proposed. Our new, revised explanation arises from a subsequent comparative study with homologous systems. ${ }^{54}$ In the solid state only the cis arrangement is found. ${ }^{16}$ On the basis of this, we proposed ${ }^{15}$ that, of the two isomers $\mathbf{L}-\mathbf{1}$ found in solution (with a relative abundance of 1:0.3), the most abundant corresponds to a cis arrangement. The gas phase calculations indicate, however, that L-1cis and L-1trans have approximately the same energy, with L-1cis slightly lower $\left(0.13 \mathrm{kcal} \mathrm{mol}^{-1}\right.$, a value which falls within the error limit expected for the calculation).

Table 4 summarizes the computed isotropic ${ }^{51} \mathrm{~V},{ }^{17} \mathrm{O},{ }^{13} \mathrm{C}$, and ${ }^{1} \mathrm{H}$ chemical shifts of the complexes L-1cis, L-1trans, and $\mathbf{L}-\mathbf{3 c i s}$ (cf. shifts for $\mathbf{L}-\mathbf{2}$ cis in Table 2). The experimental solution chemical shifts, when available (from our previous NMR studies ${ }^{15}$ ), have also been included. Comparing the theoretical and the experimental results we observe absolute differences for the ${ }^{51} \mathrm{~V}$ chemical shifts of the dioxo vanadium centers ranging from 22.9 to $35.6 \mathrm{ppm}$, and for the oxoperoxo vanadium centers from 137.3 to $175.0 \mathrm{ppm}$. The latter errors are comparable to the results given above for $\mathbf{L}-\mathbf{2}$ cis (Table

(52) Ahmed, M.; Schwendt, P.; Marek, J.; Sivák, M. Polyhedron 2004, 23, 655-663.

(53) Kaliva, M.; Giannadaki, T.; Salifoglou, A.; Raptopoulou, C. P.; Terzis, A.; Tangoulis, V. Inorg. Chem. 2001, 40, 3711-3718.

(54) Justino, L. L. G. Ph.D. Thesis, Faculty of Sciences and Technology, University of Coimbra, Portugal, 2007. 

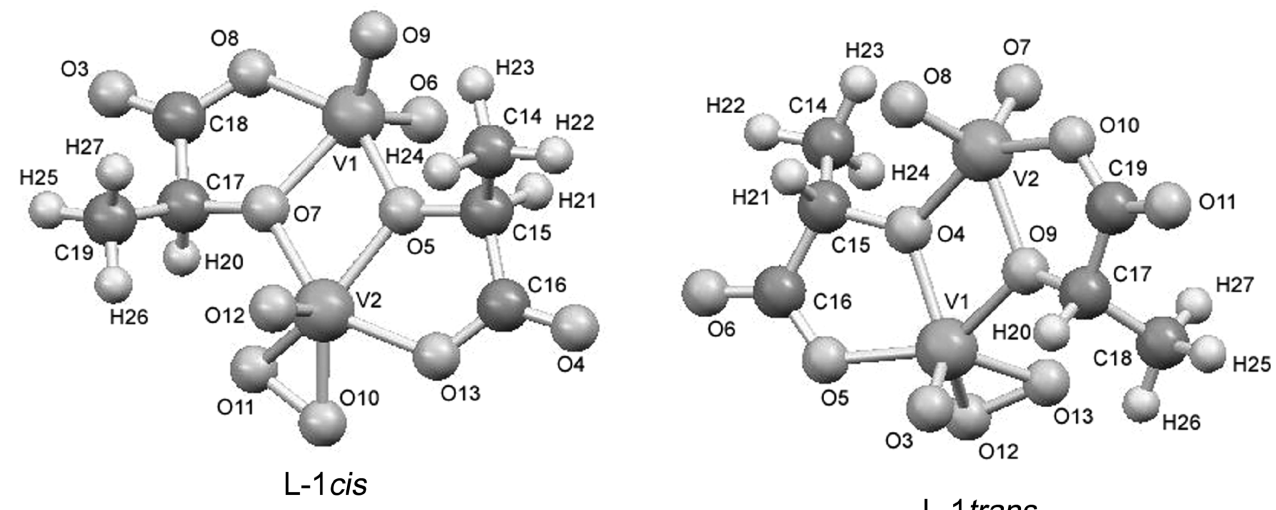

L-1 trans
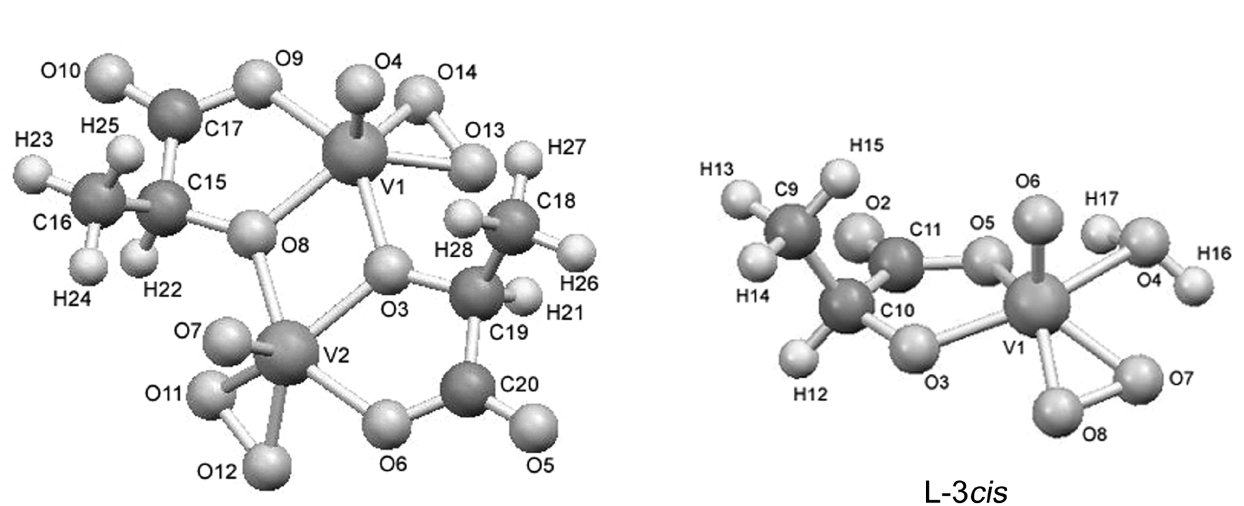

L-3cis

$\mathrm{L}-2$ cis

Figure 1. Structures of the L-lactic acid V(V) oxoperoxo complexes optimized at the B3LYP/SBKJC level.

Table 3. Selected B3LYP/SBKJC Optimized Structural Parameters (Bond Lengths in Å, Bond Angles in deg) for L-lactic Acid V(V) Complexes ${ }^{a}$

\begin{tabular}{|c|c|c|c|c|c|}
\hline \multicolumn{2}{|c|}{ L-1cis } & \multicolumn{2}{|c|}{ L-1trans } & \multicolumn{2}{|c|}{ L-3cis } \\
\hline $\mathrm{V}(1)-\mathrm{O}(9)$ & 1.6438 & $\mathrm{~V}(2)-\mathrm{O}(8)$ & 1.6448 & $\mathrm{~V}(1)-\mathrm{O}(5)$ & 2.0235 \\
\hline $\mathrm{V}(1)-\mathrm{O}(6)$ & 1.6406 & $\mathrm{~V}(2)-\mathrm{O}(7)$ & 1.6393 & $\mathrm{~V}(1)-\mathrm{O}(6)$ & 1.6124 \\
\hline $\mathrm{V}(2)-\mathrm{O}(12)$ & 1.6104 & $\mathrm{~V}(1)-\mathrm{O}(3)$ & 1.6176 & $\mathrm{~V}(1)-\mathrm{O}(7)$ & 1.8732 \\
\hline $\mathrm{V}(2)-\mathrm{O}(10)$ & 1.8839 & $\mathrm{~V}(1)-\mathrm{O}(12)$ & 1.8741 & $\mathrm{~V}(1)-\mathrm{O}(3)$ & 1.9210 \\
\hline $\mathrm{V}(2)-\mathrm{O}(11)$ & 1.8915 & $\mathrm{~V}(1)-\mathrm{O}(13)$ & 1.8718 & $\mathrm{~V}(1)-\mathrm{O}(4)$ & 2.2352 \\
\hline $\mathrm{V}(1)-\mathrm{O}(8)$ & 1.9909 & $\mathrm{~V}(2)-\mathrm{O}(4)$ & 2.0220 & $\mathrm{O}(7)-\mathrm{O}(8)$ & 1.5030 \\
\hline $\mathrm{V}(1)-\mathrm{O}(7)$ & 2.0291 & $\mathrm{~V}(2)-\mathrm{O}(9)$ & 2.0205 & $\mathrm{C}(10)-\mathrm{C}(11)$ & 1.5589 \\
\hline $\mathrm{V}(2)-\mathrm{O}(5)$ & 2.0030 & $\mathrm{~V}(1)-\mathrm{O}(5)$ & 2.0451 & $\mathrm{O}(3)-\mathrm{C}(10)$ & 1.4466 \\
\hline $\mathrm{V}(2)-\mathrm{O}(7)$ & 2.0472 & $\mathrm{~V}(1)-\mathrm{O}(9)$ & 2.0557 & $\mathrm{C}(11)-\mathrm{O}(5)$ & 1.3594 \\
\hline $\mathrm{O}(11)-\mathrm{V}(2)-\mathrm{O}(12)$ & 107.41 & $\mathrm{O}(3)-\mathrm{V}(1)-\mathrm{O}(12)$ & 109.80 & $\mathrm{O}(5)-\mathrm{V}(1)-\mathrm{O}(7)$ & 124.80 \\
\hline $\mathrm{O}(10)-\mathrm{V}(2)-\mathrm{O}(12)$ & 107.98 & $\mathrm{O}(3)-\mathrm{V}(1)-\mathrm{O}(13)$ & 109.66 & $\mathrm{O}(5)-\mathrm{V}(1)-\mathrm{O}(6)$ & 108.14 \\
\hline $\mathrm{O}(9)-\mathrm{V}(1)-\mathrm{O}(6)$ & 109.87 & $\mathrm{O}(7)-\mathrm{V}(2)-\mathrm{O}(8)$ & 109.61 & $\mathrm{O}(8)-\mathrm{V}(1)-\mathrm{O}(5)$ & 141.46 \\
\hline
\end{tabular}

${ }^{a}$ See also the structure of $\mathbf{L - 2 c i s}$ in Table 1.

2). Bühl and co-workers ${ }^{55}$ calculated the ${ }^{51} \mathrm{~V}$ shifts of a set of vanadium $(\mathrm{V})$ oxocomplexes at various theoretical levels and found a mean absolute difference between the theoretical and the experimental ${ }^{51} \mathrm{~V}$ shifts of $169 \mathrm{ppm}, 114 \mathrm{ppm}, 119$ ppm, and 118 ppm using, respectively, the SOS-DFPTLOC1/IGLO/PW91, the BP86/GIAO, the B3LYP/GIAO, and the B3LYP/IGLO approximations. Our results for the oxoperoxo centers using the UDFT-IGLO-PW91 approximation are of similar quality, whereas agreement with experiment is a bit closer for the dioxo centers. We presume that the larger errors for the oxoperoxo centers arise partly from the overestimated $\mathrm{O}-\mathrm{O}$ bond lengths. As a result, the calculations fail to reproduce the larger shielding (more negative

(55) Bühl, M.; Hamprecht, F. J. Comput. Chem. 1998, 19, 113-122. shift) of the oxoperoxo centers compared with the dioxo centers within a given complex. Bühl and Parrinello ${ }^{50}$ also calculated the ${ }^{51} \mathrm{~V}$ chemical shift for the oxodiperoxo complex $\left[\mathrm{VO}\left(\mathrm{O}_{2}\right)_{2}\left(\mathrm{H}_{2} \mathrm{O}\right)_{2}\right]^{-}$at the B3LYP/GIAO level. Computations for several structures obtained by optimization at different computational levels were performed. Depending on the structure chosen, the differences between the experimental ( $-692 \mathrm{ppm})$ and computed shifts varied from 37 to $128 \mathrm{ppm}$. In view of the total chemical shift range of vanadium (ca. $3500 \mathrm{ppm}$ ), and of the sensitivity of the shifts to small structural details, these differences can be considered as acceptable. ${ }^{55}$

In comparing the experimental and computed chemical shifts $\left({ }^{51} \mathrm{~V},{ }^{17} \mathrm{O},{ }^{13} \mathrm{C}\right.$, and $\left.{ }^{1} \mathrm{H}\right)$, we must also remember that 
Table 4. Computed and Experimental Isotropic Chemical Shifts for Three Complexes (cf. Figure 1) ${ }^{a}$

\begin{tabular}{|c|c|c|c|c|}
\hline molecule & site & $\delta$ iso $_{\text {calc }}$ & $\delta$ iso $_{\text {expt }}$ & difference (ppm) \\
\hline \multirow[t]{17}{*}{$\mathbf{L}-1 \operatorname{cis}^{b}$} & $\mathrm{~V}(1)$ & -497.5 & -520.4 & 22.9 \\
\hline & $\mathrm{V}(2)$ & -433.4 & -592.2 & 158.8 \\
\hline & $\mathrm{O}(6)$ & 1029.4 & 1054.5 & -25.1 \\
\hline & $\mathrm{O}(9)$ & 1010.8 & 1054.5 & -43.7 \\
\hline & $\mathrm{O}(10)$ & 732.8 & & \\
\hline & $\mathrm{O}(11)$ & 701.1 & & \\
\hline & $\mathrm{O}(12)$ & 1021.8 & 1188.8 & -167.0 \\
\hline & $\mathrm{C}(14)$ & 17.73 & 19.24 & -1.51 \\
\hline & $\mathrm{C}(15)$ & 90.46 & 84.69 & 5.77 \\
\hline & $\mathrm{C}(16)$ & 184.79 & $187.09^{e}$ & -2.30 \\
\hline & $\mathrm{C}(17)$ & 86.10 & 80.73 & 5.37 \\
\hline & $\mathrm{C}(18)$ & 183.96 & $186.50^{e}$ & -2.54 \\
\hline & $\mathrm{C}(19)$ & 21.94 & 21.49 & 0.45 \\
\hline & $\mathrm{H}(20)$ & 5.55 & 5.38 & 0.17 \\
\hline & $\mathrm{H}(21)$ & 3.85 & 4.47 & -0.62 \\
\hline & $\mathrm{H}(22)+\mathrm{H}(23)+\mathrm{H}(24)$ & 1.17 & 1.59 & -0.42 \\
\hline & $\mathrm{H}(25)+\mathrm{H}(26)+\mathrm{H}(27)$ & 1.36 & 1.82 & -0.46 \\
\hline \multirow[t]{17}{*}{ L-1trans ${ }^{c}$} & $\mathrm{~V}(1)$ & -421.5 & -590.6 & 169.1 \\
\hline & $\mathrm{V}(2)$ & -483.0 & -518.6 & 35.6 \\
\hline & $\mathrm{O}(3)$ & 1050.1 & & \\
\hline & $\mathrm{O}(7)$ & 1012.1 & & \\
\hline & $\mathrm{O}(8)$ & 1042.8 & & \\
\hline & $\mathrm{O}(12)$ & 716.7 & & \\
\hline & $\mathrm{O}(13)$ & 700.1 & & \\
\hline & $\mathrm{C}(14)$ & 20.57 & & \\
\hline & $\mathrm{C}(15)$ & 95.05 & 85.88 & 9.17 \\
\hline & $\mathrm{C}(16)$ & 183.15 & & \\
\hline & $\mathrm{C}(17)$ & 93.45 & 84.30 & 9.15 \\
\hline & $\mathrm{C}(18)$ & 22.89 & 23.03 & -0.14 \\
\hline & C(19) & 184.41 & & \\
\hline & $\mathrm{H}(20)$ & 4.93 & 5.54 & -0.61 \\
\hline & $\mathrm{H}(21)$ & 4.02 & 4.81 & -0.79 \\
\hline & $\mathrm{H}(22)+\mathrm{H}(23)+\mathrm{H}(24)$ & 0.95 & 1.47 & -0.52 \\
\hline & $\mathrm{H}(25)+\mathrm{H}(26)+\mathrm{H}(27)$ & 1.60 & 1.76 & -0.16 \\
\hline \multicolumn{5}{|l|}{$\mathbf{L}-2 \operatorname{cis}^{d}$} \\
\hline \multirow[t]{9}{*}{ L-3cis } & $\mathrm{V}(1)$ & -408.7 & -546.0 & 137.3 \\
\hline & $\mathrm{O}(6)$ & 1003.2 & & \\
\hline & $\mathrm{O}(7)$ & 670.5 & & \\
\hline & $\mathrm{O}(8)$ & 759.1 & & \\
\hline & $\mathrm{C}(9)$ & 21.09 & & \\
\hline & $\mathrm{C}(10)$ & 92.56 & & \\
\hline & $\mathrm{C}(11)$ & 188.44 & & \\
\hline & $\mathrm{H}(12)$ & 4.54 & & \\
\hline & $H(13)+H(14)+H(15)$ & 1.23 & & \\
\hline
\end{tabular}

${ }^{a}$ UDFT-IGLO-PW91 calculations at B3LYP/SBKJC optimized structures ${ }^{b}$ Experimental chemical shifts of complex $\mathbf{b}$ from ref 15 . $^{c}$ Experimental chemical shifts of complex $\mathbf{b}^{\prime}$ from ref $15 .{ }^{d}$ See Table $2 .^{e}$ There is the possibility of a reverse assignment between $\mathrm{C}(16)$ and $\mathrm{C}(18)$.

the experimental shifts were obtained in solution at approximately $293 \mathrm{~K}$, while the theoretical calculations involve optimization of the isolated molecule in the gas phase at low pressure, and calculation of the absolute shielding constants for the static molecule in its equilibrium geometry. In this procedure it is assumed that the temperature effects (rovibrational effects) and the zero-point energy and solvent effects on the chemical shifts are small. Explicitly, it is assumed that these effects are similar for the molecules under consideration and for the reference compounds, for which the shielding constants have also been calculated. ${ }^{50}$

Table 5 shows that, in spite of the appreciable systematic errors of the calculations, good agreement with relative ${ }^{51} \mathrm{~V}$ shifts of oxoperoxo vanadium centers can be achieved by the chosen DFT methodology. Experimental and computed $\Delta \delta\left({ }^{51} \mathrm{~V}\right)$ values, that is, the shifts upon complexation relative to the oxomonoperoxo vanadate $\left[\mathrm{VO}(\mathrm{OO})\left(\mathrm{H}_{2} \mathrm{O}\right)_{3}\right]^{+}$, are provided for the complexes of Figure 1. For three of the four complexes, the calculations correctly predict that the magnetic shielding of the metal is larger in the dinuclear complex than for the oxoperoxo vanadate $\left[\mathrm{VO}(\mathrm{OO})\left(\mathrm{H}_{2} \mathrm{O}\right)_{3}\right]^{+}$ (i.e., $\Delta \delta<0$ ). Additionally, the calculations correctly predict that the metal is more shielded in L-1cis, L-1trans, and $\mathbf{L}-2$ cis than in $\mathbf{L}-\mathbf{3}$ cis. The very small $\Delta \delta$ value with the latter complex appears to be below the uncertainties of this approach.

Some problems with the treatment of the oxoperoxo vanadium groups are also apparent from the ${ }^{17} \mathrm{O}$ shifts of the oxo groups (Tables 2 and 4). Deviations from experiment for the dioxo vanadium centers are only about $25-44 \mathrm{ppm}$. In contrast, the mono-oxoperoxo centers exhibit much larger deviations of about $160 \mathrm{ppm}$. We attribute this mainly to the overestimated $\mathrm{O}-\mathrm{O}$ bond lengths (see above). In spite of these deficiencies, the calculations correctly reproduce the observation that the magnetic shielding of the oxo oxygen nuclei of the oxoperoxo centers is larger in either $\mathbf{L}-\mathbf{1}$ cis or L-2cis (the only complexes for which experimental ${ }^{17} \mathrm{O}\left(\mathrm{V}=\mathrm{O}\right.$ ) are available) than in $\left[\mathrm{VO}(\mathrm{OO})\left(\mathrm{H}_{2} \mathrm{O}\right)_{3}\right]^{+}$(for L-1cis, $\Delta \delta_{\text {expt }}=-51 \mathrm{ppm}$ and $\Delta \delta_{\text {calc }}=-152 \mathrm{ppm}$; for L-2cis, $\Delta \delta_{\text {expt }}=-61 \mathrm{ppm}$ and $\Delta \delta_{\text {calc }}=-142 \mathrm{ppm}$ ). The corresponding shifts of the peroxo oxygen atoms have not been observed experimentally, most probably because of broadening arising from fast relaxation. However, the computed shifts predicted for these nuclei are about $300 \mathrm{ppm}$ more shielded than those of the oxo groups. This is consistent with the experimental ${ }^{17} \mathrm{O}(\mathrm{O}-\mathrm{O})$ shifts of $[\mathrm{VO}(\mathrm{OO})]^{+}(660$ ppm) and of $\mathrm{VO}(\mathrm{OO})(\mathrm{pic})\left(\mathrm{H}_{2} \mathrm{O}\right)_{2}(641 \mathrm{ppm})^{56}$ and with previous experimental ${ }^{17} \mathrm{O}$ data for an oxoperoxo complex of rhenium(VII). ${ }^{57}$

For the ${ }^{13} \mathrm{C}$ and ${ }^{1} \mathrm{H}$ chemical shifts, we obtained absolute differences between theoretical and experimental shifts ranging from 0.14 to $9.17 \mathrm{ppm}$ and 0.15 to $0.79 \mathrm{ppm}$, respectively. As mentioned above, the differences between experimental and predicted shifts are partially explained by the neglect of rovibrational, solvation, and H-bonding effects. These are especially important in the case of ${ }^{1} \mathrm{H}$ chemical shifts and may lead to significant errors. Figures $2 \mathrm{a}$ and $2 \mathrm{~b}$ show, respectively, the plots of $\delta\left({ }^{13} \mathrm{C}\right)_{\text {expt }}$ versus $\delta\left({ }^{13} \mathrm{C}\right)_{\text {calc }}$ and $\delta\left({ }^{1} \mathrm{H}\right)_{\text {expt }}$ versus $\delta\left({ }^{1} \mathrm{H}\right)_{\text {calc }}$ for the complexes of Figure 1. A perfect correlation would give a slope of unity. The slope for the ${ }^{13} \mathrm{C}$ correlation is very good $(1.02)$ whereas the ${ }^{1} \mathrm{H}$ correlation is slightly poorer $(0.95)$. Other error sources that affect all the chemical shifts are deficiencies of the exchangecorrelation functionals, the absence of current-dependent terms in the functionals used, errors due to the fact that the basis sets are (inevitably) finite, and the neglect of relativistic effects (which are expected to be small for $3 \mathrm{~d}$ complexes $^{58}$ ).

L-1cis has two nonequivalent lactate molecules (cf. Figure 1). One unresolved question in our previous NMR paper ${ }^{15}$ was the attribution of the two sets of experimental ${ }^{13} \mathrm{C}$ and ${ }^{1} \mathrm{H}$ shifts assigned to $\mathbf{L}-\mathbf{1}$ cis to the corresponding two

(56) Reynolds, M. S.; Butler, A. Inorg. Chem. 1996, 35, 2378-2383.

(57) Herrmann, W. A.; Fischer, R. W.; Scherer, W.; Rauch, M. U. Angew. Chem., Int. Ed. Engl. 1993, 32, 1157-1160.

(58) Kaupp, M.; Malkina, O. L.; Malkin, V. G. J. Chem. Phys. 1997, 106, 9201-9212; and references therein. 
Justino et al.

Table 5. Computed and Experimental ${ }^{51} \mathrm{~V}$ Chemical Shifts and $\Delta \delta$ Values ${ }^{a}$

\begin{tabular}{|c|c|c|c|c|c|c|c|}
\hline \multirow{4}{*}{$\begin{array}{l}\text { L-1 cis }\left[\mathrm{V}_{2} \mathrm{O}_{3}(\mathrm{OO})(\mathrm{L}-\mathrm{lact})_{2}\right]^{2-} \\
\text { L-1trans }\left[\mathrm{V}_{2} \mathrm{O}_{3}(\mathrm{OO})(\mathrm{L}-\mathrm{lact})_{2}\right]^{2-} \\
\text { L-2 cis }\left[\mathrm{V}_{2} \mathrm{O}_{2}(\mathrm{OO})_{2}(\mathrm{~L}-\mathrm{lact})_{2}\right]^{2-} \\
\mathbf{L - 3} \text { cis }\left[\mathrm{VO}(\mathrm{OO})(\mathrm{L}-\mathrm{lact})\left(\mathrm{H}_{2} \mathrm{O}\right)\right]^{-}\end{array}$} & \multicolumn{2}{|c|}{$\delta_{\text {expt }}^{b}$} & \multirow{2}{*}{$\frac{\Delta \delta_{\text {expt }}^{c}}{-55.9}$} & \multicolumn{2}{|c|}{$\delta_{\text {calc }^{a}}^{a}$} & \multicolumn{2}{|c|}{$\Delta \delta_{\text {calc }^{c}}$} \\
\hline & $(-520.4)^{d}$ & -592.2 & & $(-497.5)$ & -433.4 & & -20.8 \\
\hline & $(-518.6)$ & -590.6 & -54.3 & $(-483.0)$ & -421.5 & & -8.9 \\
\hline & & -595.9 & -59.6 & -419.9 & -421.9 & -7.3 & -9.3 \\
\hline
\end{tabular}

${ }^{a}$ Computational results at UDFT-IGLO-PW91//B3LYP/SBJKC level, relative to $\mathrm{VOCl}_{3}\left(\sigma\left({ }^{51} \mathrm{~V}\right)=-1945.7 \mathrm{ppm}\right) .{ }^{b} \mathrm{Cf}$. ref $15 .{ }^{c} \Delta \delta=\delta_{\text {complex }}-$ $\delta\left[\mathrm{VO}(\mathrm{OO})\left(\mathrm{H}_{2} \mathrm{O}\right)_{3}\right]^{+}$; applied only to the peroxo $\mathrm{V}(\mathrm{V})$ centers. $\delta_{\text {expt }}\left[\mathrm{VO}(\mathrm{OO})\left(\mathrm{H}_{2} \mathrm{O}\right)_{3}\right]^{+}=-536.3 \mathrm{ppm} ; \delta_{\text {calc }}\left[\mathrm{VO}(\mathrm{OO})\left(\mathrm{H}_{2} \mathrm{O}\right)_{3}\right]^{+}=-412.6$ ppm. ${ }^{d} \mathrm{Values}$ in parentheses refer to the $\mathrm{V}(\mathrm{V})$ dioxo centers.

a)

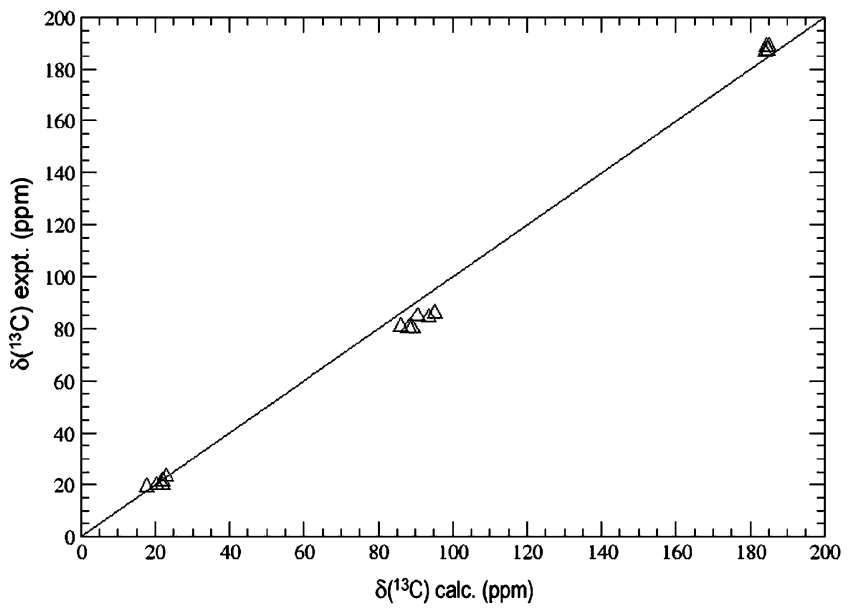

b)

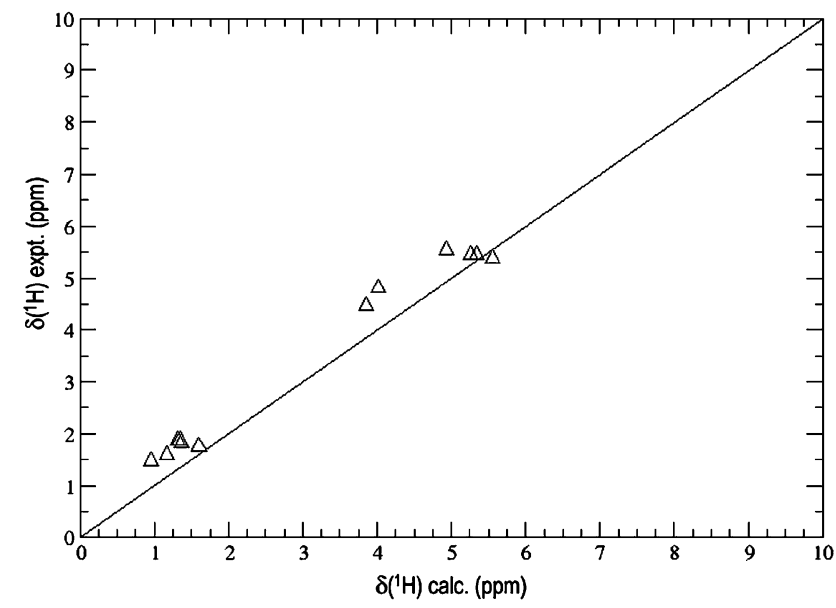

Figure 2. Experimental vs calculated (a) ${ }^{13} \mathrm{C}$ and (b) ${ }^{1} \mathrm{H}$ chemical shifts for the complexes of Figure 1 (computed using the UDFT-IGLO-PW91 approximation for the B3LYP/SBKJC geometries); ideal lines (slope $=1$ ) are included.

molecules. The same problem was observed with L-1trans. The present calculations of the shifts reveal a clear correspondence between the calculated and the experimental shifts for the lactate molecules in each complex. This enables the reliable assignment of the spectra (as given in Table 4).

III. Structural Aspects. We will now discuss some structural features commonly observed in the structures of oxoperoxo vanadium $(\mathrm{V})$ complexes of $\alpha$-hydroxycarboxylic acids. In our previous studies of the complexation of $\mathrm{V}(\mathrm{V})$ and peroxide in solution with glycolic, ${ }^{59}$ L-lactic, ${ }^{15}$ and

(59) Justino, L. L. G.; Ramos, M. L.; Caldeira, M. M.; Gil, V. M. S. Inorg. Chim. Acta 2000, 311, 119-125.
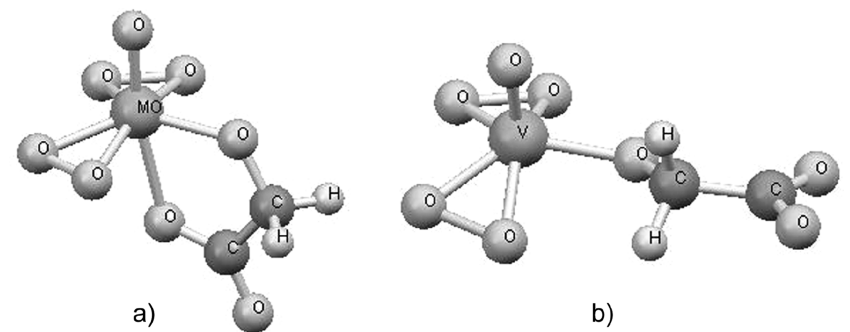

Figure 3. Optimized structures (B3LYP/SBKJC) of (a) oxodiperoxo complex of Mo(VI) with glycolic acid and (b) hypothetical oxodiperoxo complex of $\mathrm{V}(\mathrm{V})$ with glycolic acid. In both cases a structure having a bidentate coordination of the acid was considered as a starting point.

L-malic acids ${ }^{60}$ we found that $\mathrm{V}(\mathrm{V})$ forms oxomonoperoxo vanadium complexes, that is, one peroxide unit per vanadium center; with lactic acid an oxodiperoxovanadium ${ }^{61}$ complex is also formed but in very small concentration. Other metals form oxodiperoxo complexes with these and related ligands, for example, molybdenum(VI), for which only oxodiperoxo complexes of glycolic acid are known. ${ }^{62} \mathrm{~A}$ further interesting feature is that the $\mathrm{V}_{2} \mathrm{O}_{2}$ core, observed by $\mathrm{X}$-ray diffraction in the solid-state structures of the dinuclear $\mathrm{V}(\mathrm{V})$ oxoperoxo complexes, always involves hydroxylate oxygen atoms from the deprotonated acid bridging the two vanadium atoms, and there is never an involvement of carboxylate oxygen atoms. A third characteristic common to the solution behavior of these three ligand systems is that they do not form complexes with 1:2 metal/acid stoichiometry. We have used B3LYP/ SBKJC optimizations to see whether computations allow us to rationalize and reproduce these features.

(a) Oxoperoxocomplexes of $\alpha$-Hydroxycarboxylic Acids: Comparison Between $\mathrm{V}(\mathrm{V})$ and $\mathrm{Mo}(\mathrm{VI})$. As discussed above, molybdenum(VI) forms a diperoxo complex $^{62}$ with glycolic acid, while vanadium(V) forms monoperoxo complexes with this and other $\alpha$-hydroxycarboxylic acids. With other types of ligands, $\mathrm{V}(\mathrm{V})$ may also form diperoxo complexes. We have optimized the structure of a diperoxo complex of $\mathrm{Mo}(\mathrm{VI})$ with glycolic acid, and its equilibrium geometry is shown in Figure $3 \mathrm{a}$. We have also optimized a structure homologous to this but with $\mathrm{V}$ replacing Mo (Figure 3b). We can see that, while glycolate keeps its bidentate coordination to the metal in the Mo complex, with $\mathrm{V}(\mathrm{V})$ it loses one of its coordination positions. The lack of stability of a diperoxo complex for $\mathrm{V}(\mathrm{V})$ with this type of ligand is likely to be related to the high negative charge $(-3$

(60) Justino, L. L. G.; Ramos, M. L.; Caldeira, M. M.; Gil, V. M. S. Inorg. Chim. Acta 2003, 356, 179-186.

(61) Gorzsás, A.; Andersson, I.; Pettersson, L. Dalton Trans. 2003, $2503-$ 2511.

(62) Dengel, A. C.; Griffith, W. P.; White, A. J. P. J. Chem. Soc., Dalton Trans. 1987, 991-995. 


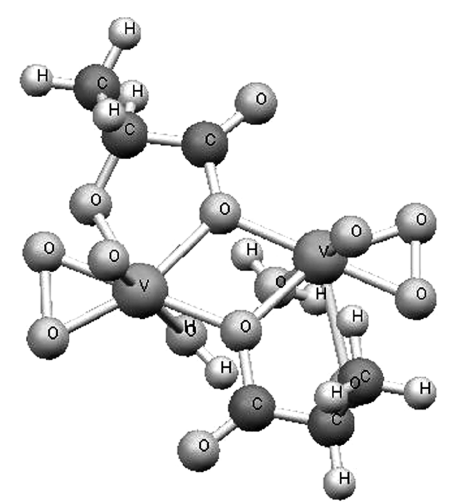

a)

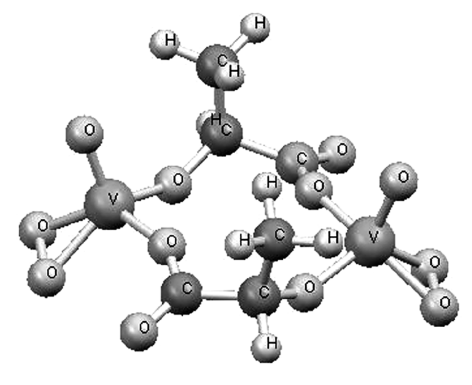

b)

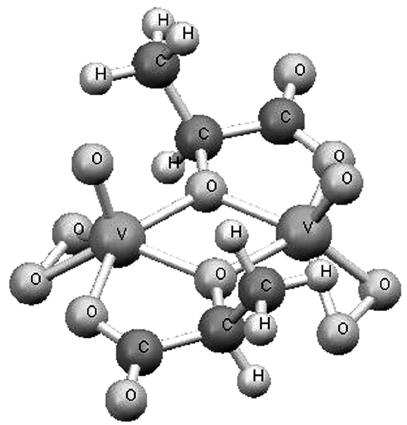

c)

Figure 4. (a) Structure in which the carboxylate groups bridge the vanadium atoms, used as starting point for optimization (B3LYP/SBKJC); (b) optimized geometry of (a); (c) optimized geometry of $\mathbf{L - 2 c i s , ~ i n ~ w h i c h ~ t h e ~ h y d r o x y l a t e ~ g r o u p s ~ b r i d g e ~ t h e ~ v a n a d i u m ~ a t o m s . ~}$

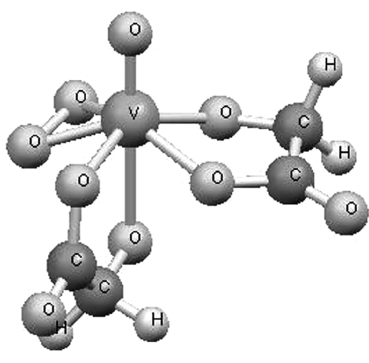

a)

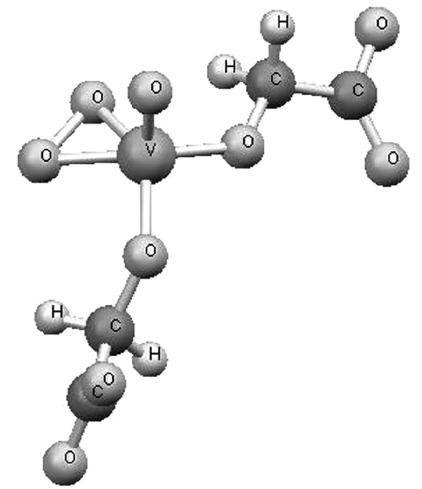

b)
Figure 5. (a) Starting point for optimization; (b) optimized structure of (a) (B3LYP/SBKJC).

vs -2 for the Mo complex). While the charge is partly compensated by the counterions and further interactions in the condensed phase, there is still a reluctance to form a diperoxo complex.

(b) $\mathrm{V}_{2} \mathrm{O}_{2}$ Core Involving a Hydroxylate Bridge. Figure 4a shows a hypothetical structure of a peroxo vanadium(V) complex of L-lactic acid in which the oxygen atoms of the carboxylate groups are involved in the formation of the bridges between the vanadium atoms. We have used this structure as a starting point for the optimization, the result being the equilibrium geometry of Figure $4 \mathrm{~b}$. We found that the central $\mathrm{V}_{2} \mathrm{O}_{2}$ unit was destroyed during the optimization, leading to the formation of a ten-sided, highly unstable ring. This structure is higher in energy by $12.5 \mathrm{kcal} \mathrm{mol}^{-1}$ relative to L-2cis, presented before (and also shown in Figure 4c for comparison), in which the hydroxylate groups bridge the vanadium atoms. These results show that the computational model allows us to correctly obtain higher stability with the involvement of the hydroxylate groups of the acid in the formation of the $\mathrm{V}_{2} \mathrm{O}_{2}$ core.

(c) Complexes $\mathrm{VO}(\mathrm{OO})($ acid $)\left(\mathrm{H}_{2} \mathrm{O}\right)$ vs Complexes $\mathrm{VO}(\mathrm{OO})(\mathbf{a c i d})_{2}$. The optimization of a structure with 1:2:1 vanadium/glycolic acid/peroxide stoichiometry, VO(OO)$(\text { gly })_{2}$, in which the glycolate groups are bidentate (Figure 5a), results in a geometry in which the two glycolate ligands bind to the metal only through the oxygen atoms of the hydroxylate groups (Figure 5b). This kind of structure is, probably, not as stable as $\mathrm{VO}(\mathrm{OO})(\mathrm{gly})\left(\mathrm{H}_{2} \mathrm{O}\right)$, which forms in solution, and in which the acid coordinates through both the functional groups with an additional water ligand. Again, the high negative charge $(-3)$ of the complex may disfavor the 1:2:1 stoichiometrical composition.

\section{Conclusions}

Within the context of the role of vanadium(V) species in biology and as potential catalysts, this study has evaluated the performance of various DFT methods (exchange-correlation functional, pseudopotentials, and basis sets) for reproducing the solid- and solution-state structures of a family of dinuclear vanadium oxoperoxo complexes. This was done by (a) direct comparison of optimized gas-phase and experimental solid-state structure parameters for one specific complex and (b) by comparison of computed (gasphase) and experimental (solution) multinuclear NMR data for a series of complexes.

On the basis of B3LYP/SBJKC optimized structures, the NMR chemical shifts were computed at the UDFT-IGLOPW91 level. Despite obvious systematic shortcomings, such as limitations of existing exchange-correlation functionals, and, in particular, neglect of environmental and dynamical effects in solution, an acceptable predictive power of this ansatz has been found. For example, relative ${ }^{51} \mathrm{~V}$ shifts between different complexes are reproduced reasonably well. The same holds for ${ }^{17} \mathrm{O}$ (oxo) chemical shifts. The calculations have also allowed the assignment of previously unclear ${ }^{13} \mathrm{C}$ and ${ }^{1} \mathrm{H}$ shifts to magnetically inequivalent ligands of identical composition.

We believe that such computational methods may contribute to resolving uncertainties in the attribution of structures of vanadium complexes, both in the solid state and in solution. We have been able to rationalize and even predict some particular structural features of these complexes in the solid state and some aspects of the aqueous solution chemistry of the systems, in particular the bridging of the vanadium atoms in the $\mathrm{V}_{2} \mathrm{O}_{2}$ core of dinuclear complexes by hydroxylate bridges, the preference for $1: 1$ vanadium: peroxide stoichiometry, and the very low stability of complexes with 1:2 vanadium/acid stoichiometry. It is hoped that such methods will be useful also in other cases for 
predicting structural aspects and the solution speciation of more complex metal systems, as well as for systems for which there are experimental difficulties in characterizing complexation equilibria.

Acknowledgment. L.L.G.J. thanks "Fundação para a Ciência e a Tecnologia" of the Portuguese Ministry for Science, Technology and Higher Education, for the postdoctoral grant SFRH/BPD/26415/2006, and the "Laboratório de Computação Avançada" of the Department of Physics of the University of Coimbra for the computing facilities (Milipeia Cluster). L.L.G.J. also wishes to thank Profs. Vladimir G. Malkin and Olga L. Malkina for helpful discussions. A.J.F.N.S. thanks "Fundação para a Ciência e a Tecnologia" for the financial support (POCI/AMB/55281/ 2004). Work in Würzburg has been supported by Deutsche Forschungsgemeinschaft (Project No. KA1187/5-1/5-2).

IC800405X 